\title{
INCLUSÃO DE ESTUDANTES COM DEFICIÊNCIA NA EDUCAÇÃO SUPERIOR NA PERSPECTIVA DA GESTÃO UNIVERSITÁRIA
}

\author{
JOANA MARIA DE MORAES COSTA ${ }^{1}$ \\ ORCID: https://orcid.org/0000-0002-4504-1442
}

TANIA MARA ZANCANARO PIECZKOWSKI ${ }^{2}$

ORCID: https://orcid.org/0000-0002-5257-7747

\begin{abstract}
RESUMO: O texto aborda uma pesquisa que investigou como o acesso de estudantes com deficiência na educação superior reverbera nas práticas de gestão universitária no que se refere aos direitos desse público. Nesse sentido, buscamos compreender os efeitos da presença de estudantes com deficiência nos programas e políticas institucionais relativas à inclusão. Foram entrevistados gestores atuantes em quatro universidades, localizadas no oeste de Santa Catarina: uma pública federal, uma pública estadual, uma comunitária e uma privada. Por meio de entrevistas narrativas, foram geradas materialidades empíricas, posteriormente analisadas na perspectiva da análise do discurso, com referenciais foucaultianos. O estudo aponta os efeitos dos discursos normativos da inclusão na subjetivação dos gestores e os posicionamentos frente às demandas. Constatamos que as políticas governamentais de inclusão, materializadas, inclusive, nos instrumentos de avaliação dos cursos e das instituições de educação superior aplicados pelo Ministério da Educação, mobilizam os gestores a investirem esforços na inclusão.
\end{abstract}

Palavras-chave: Estudantes com deficiência, Políticas de Inclusão, Gestão Universitária.

\section{INCLUSION OF STUDENTS WITH DISABILITIES IN HIGHER EDUCATION FROM THE PERSPECTIVE OF UNIVERSITY MANAGEMENT}

\begin{abstract}
This text addresses a research that investigated how the access of students with disabilities in college education reverberates in the institution management practices with regard to the rights of this group. In this sense, we seek to understand the effects in programs and institutional policies related to inclusion of disabled students. We interviewed managers who have been working in four colleges located in the west of Santa Catarina: a federal, a state, a community and a private ones. By means of narrative interviews, empirical materialities were generated, later analyzed in the perspective of discourse analysis, under Foucaultian references. The study points out the effects of the normative discourses of inclusion on the subjectivation of the managers and their positioning about requirements. We realize that government inclusion policies, materialized in the
\end{abstract}

\footnotetext{
${ }^{1}$ Universidade Comunitária da Região de chapecó - UNOCHAPECO. Chapecó-SC/Brasil <joana@unochapeco.edu.br>.

${ }^{2}$ Universidade Comunitária da Região de chapecó - UNOCHAPECO. Chapecó-SC/Brasil <taniazp@unochapeco.edu.br>
} 
evaluation instruments of the courses and institutions of higher education applied by the Ministry of Education, mobilize managers to invest in inclusion.

Keywords: Disabled Students, Inclusion Policies, Institution Management.

\title{
INCLUSIÓN DE ESTUDIANTES CON DISCAPACIDADES EN LA EDUCACIÓN SUPERIOR DESDE LA PERSPECTIVA DE LA GESTIÓN UNIVERSITARIA
}

\begin{abstract}
RESÚMEN: El texto analiza una investigación que abordó la temática de cómo el acceso de los estudiantes con discapacidades a la educación superior repercute en las prácticas de gestión universitaria respecto a los derechos de este grupo. En este sentido, buscamos comprender los efectos de la presencia de estudiantes con discapacidades en programas institucionales y políticas relacionadas con la inclusión. Se entrevistó a gestores activos en cuatro universidades, ubicadas en el oeste de Santa Catarina: una pública federal, un pública provincial, una comunitaria y una privada. A través de entrevistas narrativas se generaron materiales empíricos, luego analizados desde la perspectiva del análisis del discurso, con referencias de Foucault. El estudio señala los efectos de los discursos normativos de inclusión sobre la subjetividad de los gestores y sus posicionamientos en relación con las demandas. Constantamos que las políticas de inclusión del gobierno, materializadas incluso en los instrumentos para evaluar cursos e instituciones de educación superior por el Ministerio de Educación, alientan a los gestores a invertir esfuerzos en implementar las políticas de inclusión.
\end{abstract}

Palabras clave: Estudiantes con discapacidad, políticas de inclusión, gestión universitaria.

\section{INTRODUÇÃO}

Este artigo foi inspirado em uma pesquisa que abordou a inclusão de estudantes com deficiência na Educação Superior na perspectiva da gestão universitária. Nesse sentido, buscamos compreender a relação entre os imperativos legais da inclusão de estudantes com deficiência na Educação Superior e como as verdades contemporâneas sobre a inclusão na universidade influenciam os gestores na definição de políticas institucionais. Nos amparamos na perspectiva pós-estruturalista de pesquisa, que alerta para "abrir mão de enfoques teóricos que priorizam o caráter explicativo e prescritivo do conhecimento para assumir enfoques que estimulam a desnaturalização e a problematização das coisas que aprendemos a tomar como dadas" (MEYER; PARAÍSO, 2014, p. 59).

Vivemos tempos de ampliação de acesso de estudantes com deficiência às instituições de educação superior, e várias pesquisas têm sido publicadas acerca da temática. Realizamos buscas nos bancos de dados do Conselho Nacional de Desenvolvimento Científico e Tecnológico - CNPq; no site da Associação Nacional de Pós-Graduação e Pesquisa em Educação - ANPEd, no recorte temporal de 2008 a 2014, e localizamos estudos que evidenciam a inclusão na educação superior na perspectiva dos próprios estudantes com deficiência, dos professores, das famílias; outros que abordam as políticas de educação inclusiva, as estatísticas oficiais que explicitam o aumento no número de matrículas, entre outras. Contudo, não localizamos estudos que mencionem a complexidade do processo de inclusão na perspectiva dos gestores universitários, considerando que, neste empreendimento, surge a necessidade de enfrentar barreiras arquitetônicas, atitudinais, programáticas, instrumentais, comunicacionais, que foram sendo construídas e até naturalizadas ao longo dos tempos.

Constatamos que as verdades acerca das pessoas com deficiência são mutáveis. Se na antiguidade e medievalidade, esse público era exterminado, escondido, ignorado; se na modernidade foi categorizado, classificado; na contemporaneidade, passa a ser compreendido como detentor de direitos, incluindo o direito à diferença. Contudo, o debate em torno do respeito ou do reconhecimento às diferenças representa um paradoxo frente a discursos de ódio e preconceito que têm sido disseminados 
na sociedade, em relação a identidades distintas. Quando afirmamos uma identidade ou marcamos a diferença, estamos tratando de relações de poder e, nesse sentido, Silva alerta que:

[...] antes de tolerar, respeitar e admitir a diferença, é preciso explicar como ela é ativamente produzida. Uma estratégia que simplesmente admita e reconheça o fato da diversidade torna-se incapaz de fornecer os instrumentos para questionar precisamente os mecanismos e as instituições que fixam as pessoas em determinadas identidades culturais e que as separam por meio da diferença cultural (2014, p. 100).

Quando mencionamos aspectos de tratamentos históricos, não o fazemos com a ingenuidade de acreditar que houve uma única forma de tratar as pessoas com deficiência ao longo da história. Bem sabemos que a história linear e generalizante é uma invenção de quem tem o poder de narrá-la. Para Foucault, as verdades são produzidas no curso da história, permeadas pelas relações de poder. As sociedades possuem o seu regime de verdade, dependendo do contexto de determinadas épocas. Para Foucault:

A verdade é deste mundo; ela é produzida nele graças a múltiplas coerções e nele produz efeitos regulamentados de poder. Cada sociedade tem seu regime de verdade e sua 'política geral' de verdade: isto é, os tipos de discurso que ela acolhe e faz funcionar como verdadeiros; os mecanismos e as instâncias que permitem distinguir os enunciados verdadeiros dos falsos, a maneira como se sanciona uns e outros; as técnicas e os procedimentos que são valorizados para a obtenção da verdade; o estatuto daqueles que têm o encargo de dizer o que funciona como verdadeiro (FOUCAULT, 2011, p. 12).

$\mathrm{Na}$ contemporaneidade, a inclusão está permeada pelas narrativas amparadas numa visão inquestionável e pouco problematizada, em que os avanços na democratização e expansão do acesso à universidade são representados através de números estatísticos divulgados como promissores. Nesse contexto, nos desafiamos a tensionar algumas verdades postas, como a reflexão sobre os processos que compõem a trama de fios que tecem o contexto da inclusão de estudantes com deficiência na universidade. Para Veiga-Neto (2007, p. 23):

Todos nós que hoje exercemos a docência ou a pesquisa em Educação tivemos uma formação intelectual e profissional em moldes iluministas. Uma das consequências disso é que talvez não estejamos suficientemente aptos para enfrentar, nem mesmo na vida privada, as rápidas e profundas mudanças culturais, sociais, econômicas e políticas em que nos achamos mergulhados.

Deste modo, as políticas de inclusão funcionam como dispositivos políticos a serviço da segurança da população e os procedimentos de controle e delimitação dos discursos, geram efeitos de subjetivação. Recorremos às noções foucaultianas, através de Revel, que define subjetivação como

[...] um processo pelo qual se obtém a constituição de um sujeito, ou, mais exatamente, de uma subjetividade. Os 'modos de subjetivação' ou 'processos de subjetivação' do ser humano correspondem, na realidade, a dois tipos de análise: de um lado, os modos de objetivação que transformam os seres humanos em sujeitos - o que significa que há somente sujeitos objetivados e que os modos de subjetivação são, nesse sentido, práticas de objetivação; de outro lado, a maneira pela qual a relação consigo, por meio de um certo número de técnicas, permite constituir-se como sujeito de sua própria existência (REVEL, 2005, p. 82).

Apesar das transformações pelas quais passa a educação superior, a expansão não democratizou efetivamente esse nível de ensino, que historicamente evidencia marcas da seleção e da exclusão. O ingresso, especialmente nas instituições de educação superior privadas, está mais facilitado, decorrente de ampliação de vagas para esse nível de ensino, nos últimos anos. Contudo, muitos estudantes em idade de frequentar a educação superior continuam excluídos, tenham eles deficiência ou não. Outros ingressam, mas não concluem os cursos. 
O acesso, a permanência e a aprendizagem de estudantes com deficiência são potencializados por políticas de inclusão e acessibilidade, o que vai além de determinações legais e até mesmo da boa vontade ou possibilidades dos gestores das instituições de educação superior.

Concordamos com Pieczkowski e Naujorks (2014, p. 130) quando afirmam que "o termo inclusão vem sendo utilizado indiscriminadamente, adotado como um conceito da moda, em praticamente todos os setores da sociedade como uma necessidade autojustificada e evidente por si mesma". Contudo, os bastidores desse cenário podem revelar perversidades.

\section{CAMINHO TEÓRICO METODOLÓGICO}

Iniciamos esse tópico com uma referência a Costa, que afirma que:

A originalidade da pesquisa está na originalidade do olhar. Os objetos não se encontram no mundo à espera de alguém que venha estudá-los. Para um objeto ser pesquisado é preciso que uma mente inquiridora, munida de um aparato teórico fecundo, problematize algo de forma a constituí-lo em objeto de investigação. O olhar inventa o objeto e possibilita a interrogação sobre ele. (COSTA, 2007, p. 148).

Noutras palavras, a escolha das lentes teóricas perpassa todas as etapas da pesquisa, desde o modo de perguntar, de pensar o objeto de investigação, as formas de análise das materialidades empíricas, até a própria identidade da pesquisa.

Meyer e Paraíso ressaltam que a metodologia de construção da pesquisa é entendida como "um certo modo de perguntar, de interrogar, de formular questões e de construir problemas de pesquisa que é articulado a um conjunto de procedimentos de coleta de informações [...]" (MEYER; PARAÍSO, 2014, p. 18).

Para escrever esse texto elegemos um dos agrupamentos temáticos da pesquisa que constitui a dissertação de mestrado na qual as autoras deste artigo estão envolvidas, no papel de autoria ou orientação. Ademais, ampliamos o texto com considerações que não estão presentes na dissertação, as quais discutem como o acesso de estudantes com deficiência na educação superior reverbera nas práticas de gestão universitária no que se refere aos direitos desse público. Ou seja, o artigo aborda a percepção dos gestores universitários sobre o aumento de matrículas de estudantes com deficiência na universidade e as condições de atendimento às políticas de inclusão, fatores que se constituem como elementos de avaliação e regulação dos cursos e das instituições.

Foram entrevistados oito gestores universitários, atuantes em quatro Instituições de Educação Superior (IES) inseridas no município de Chapecó: uma pública federal; uma pública estadual; uma comunitária e uma privada. Chapecó localiza-se no Oeste de Santa Catarina, tem aproximadamente duzentos e dez mil habitantes (210.000) e conta com 25 IES (comunitárias, públicas ou privadas), que oferecem ensino presencial e/ou a distância.

O critério para a seleção das IES foi: a) localização na cidade de Chapecó; b) pertencer às distintas categorias administrativas mencionadas; e c) estar entre as instituições com maior número de estudantes matriculados, dentre eles, estudantes com deficiência.

$\mathrm{Na}$ sequência, quadro 1, evidenciamos algumas características das instituições pesquisadas.

Quadro 1 - Caracterização das instituições pesquisadas

\begin{tabular}{|l|l|l|l|l|}
\hline $\begin{array}{c}\text { Identificação da } \\
\text { Universidade }\end{array}$ & $\begin{array}{c}\text { Número de } \\
\text { estudantes } \\
\text { matriculados }\end{array}$ & $\begin{array}{c}\text { Estudantes com deficiência } \\
\text { matriculados na ocasião da pesquisa }\end{array}$ & $\begin{array}{c}\text { Ano de } \\
\text { Fundação }\end{array}$ & $\begin{array}{c}\text { Estrutura } \\
\text { Multicampi }\end{array}$ \\
\hline Universidade A & 8.000 estudantes & 46 estudantes (campi) & 2009 & 6 campi \\
\hline Universidade B & 15.000 estudantes & 1 (no centro) & 1965 & 12 campi \\
\hline Universidade C & 8.000 estudantes & 87 estudantes (campi) & 1970 & 3 campi \\
\hline Universidade D & 300.000 estudantes & 3 (na unidade) & 1976 & 450 Municípios \\
\hline
\end{tabular}


Fonte: elaborado pelas autoras (com base nas informações retiradas dos sites das universidades, das entrevistas e disponibilizadas pelos setores de acessibilidade).

O critério de definição dos gestores entrevistados foi estabelecido pela função exercida na instituição, como diretor acadêmico, diretor administrativo ou equivalente. São profissionais que ocupavam, no período da pesquisa, cargos de gestão, que possuíam atribuições referentes às demandas que envolvem as ações de acessibilidade e inclusão de estudantes com deficiência nas universidades. $\mathrm{O}$ nome do cargo está de acordo com a organização e a estrutura hierárquica de cada instituição pesquisada.

As entrevistas ocorreram com os gestores que atuavam no campus universitário estruturado no município de Chapecó/SC, porém a caracterização e os dados dos estudantes são os gerais de cada instituição. Devido à especificidade das atividades da gestão universitária, essa caracterização se estende a toda estrutura da universidade, uma vez que os setores de acessibilidade atendem às demandas de todos os campi. Os gestores trabalham com uma estrutura única de recursos financeiros, de pessoal, de constituição jurídica e regras institucionais

\section{Quadro 2 - Relação e caracterização dos gestores participantes das entrevistas narrativas}

\begin{tabular}{|c|c|c|c|c|c|}
\hline Entrevistado & Universidade & $\begin{array}{l}\text { Atribuições } \\
\text { institucionais }\end{array}$ & $\begin{array}{c}\text { Formação profissional do } \\
\text { entrevistado }\end{array}$ & $\begin{array}{l}\text { Tempo } \\
\text { na IES }\end{array}$ & $\begin{array}{c}\text { Tempo de } \\
\text { atuação no } \\
\text { cargo \função }\end{array}$ \\
\hline Gestor A1 & $\begin{array}{c}\text { A- } \\
\text { Universidade } \\
\text { Pública Federal }\end{array}$ & $\begin{array}{l}\text { Técnica do } \\
\text { Núcleo de } \\
\text { Acessibilidade }\end{array}$ & $\begin{array}{l}\text { Graduação em Matemática. } \\
\text { Mestrado em Educação }\end{array}$ & 5 anos & 5 anos \\
\hline Gestor A2 & $\begin{array}{c}\text { A- } \\
\text { Universidade } \\
\text { Pública Federal } \\
\end{array}$ & $\begin{array}{l}\text { Pró-reitor de } \\
\text { Graduação }\end{array}$ & $\begin{array}{c}\text { Graduação Agronomia. Mestrado em } \\
\text { Ciência do Solo. Doutorado em } \\
\text { Ciência do Solo } \\
\end{array}$ & 4 anos & 3 anos \\
\hline Gestor B1 & $\begin{array}{l}\text { B- } \\
\text { Universidade } \\
\text { Pública } \\
\text { Estadual }\end{array}$ & $\begin{array}{c}\text { Diretor de } \\
\text { Administração }\end{array}$ & $\begin{array}{c}\text { Graduação em Matemática e } \\
\text { Computação Científica. } \\
\text { Mestrado em Matemática. } \\
\text { Doutorado em Engenharia Química }\end{array}$ & 10 anos & 3 anos \\
\hline Gestor B2 & $\begin{array}{l}\text { B- } \\
\text { Universidade } \\
\text { Pública } \\
\text { Estadual }\end{array}$ & $\begin{array}{l}\text { Diretor de } \\
\text { Ensino }\end{array}$ & $\begin{array}{c}\text { Graduação em Engenharia de } \\
\text { Alimentos. Mestrado em Ciências de } \\
\text { Alimentos }\end{array}$ & 10 anos & 3 anos \\
\hline Gestor B3 & $\begin{array}{c}\text { B- } \\
\text { Universidade } \\
\text { Pública } \\
\text { Estadual } \\
\end{array}$ & $\begin{array}{l}\text { Diretor de } \\
\text { Ensino }\end{array}$ & $\begin{array}{l}\text { Graduação em Licenciatura em } \\
\text { Física. } \\
\text { Mestrado e Doutorado em Física }\end{array}$ & 11 anos & 2 anos \\
\hline Gestor C1 & $\begin{array}{l}\text { C- } \\
\text { Universidade } \\
\text { Comunitária }\end{array}$ & $\begin{array}{l}\text { Diretor de } \\
\text { Ensino }\end{array}$ & $\begin{array}{c}\text { Graduação em Pedagogia. } \\
\text { Especialização em Educação } \\
\text { Especial e Docência na Educação } \\
\text { Superior. Mestrado e Doutorado em } \\
\text { Educação }\end{array}$ & 17 anos & 8 anos \\
\hline Gestor C2 & $\begin{array}{l}\text { C- } \\
\text { Universidade } \\
\text { Comunitária }\end{array}$ & $\begin{array}{l}\text { Técnica do } \\
\text { Setor de } \\
\text { Divisão de } \\
\text { Acessibilidade }\end{array}$ & $\begin{array}{l}\text { Graduação em Pedagogia. } \\
\text { Especialização em Educação } \\
\text { Especial }\end{array}$ & 2 meses & 2 meses \\
\hline Gestor D1 & $\begin{array}{l}\text { D- } \\
\text { Universidade } \\
\text { Privada }\end{array}$ & $\begin{array}{l}\text { Técnica do } \\
\text { Núcleo de } \\
\text { Educação } \\
\text { Inclusiva }\end{array}$ & $\begin{array}{c}\text { Graduação em Licenciatura Plena em } \\
\text { História. Graduação em andamento } \\
\text { em Ciências Sociais. }\end{array}$ & 2 anos & 2 anos \\
\hline
\end{tabular}


Fonte: elaborado pelas autoras.

De posse dos Termos de Concordância, assinados pelos responsáveis pelas instituições envolvidas no estudo e, posteriormente, com a aprovação do projeto de investigação pelo Comitê de Ética em pesquisa envolvendo seres humanos ${ }^{1}$, nos aproximamos dos sujeitos da pesquisa que, individualmente, assinaram os Termos de Esclarecimento Livre e Esclarecido. A participação dos sujeitos da pesquisa aconteceu por meio de entrevistas narrativas, gravadas e posteriormente transcritas.

A entrevista narrativa, para Andrade (2014, p. 175), "[...] é uma possibilidade de pesquisa ressignificada no campo de pesquisa pós-estruturalista em uma perspectiva etnográfica". A autora afirma, ainda, que "[...] as narrativas são constituídas a partir da conexão entre discursos que se articulam, que se sobrepõem, que se somam ou, ainda, que diferem ou contemporizam" (ANDRADE, 2014, p. 181).

As entrevistas foram direcionadas por um roteiro com tópicos relativos às demandas derivadas da presença de estudantes com deficiência na IES; à percepção acerca dos movimentos gerados pela inclusão de estudantes com deficiência nas universidades pesquisadas; às normativas acerca da inclusão de estudantes com deficiência na educação superior e como elas reverberam em políticas institucionais; aos desafios enfrentados pela gestão universitária para consolidar as políticas inclusivas para estudantes com deficiência na universidade (econômicas, de formação de pessoal, de acessibilidade arquitetônica, atitudinal, de comunicação, metodológica, digital) previstas no instrumento ministerial para credenciamento ou recredenciamento institucional, e avaliação para reconhecimento ou renovação de reconhecimento dos cursos de graduação.

As narrativas foram agrupadas tematicamente, considerando-se as recorrências discursivas que emergiram da leitura cuidadosa do material gerado, o qual foi examinado pela perspectiva da análise do discurso, amparada em referenciais foucaultianos. Nessa perspectiva, a análise não tem como intuito trabalhar com a língua como um sistema abstrato, mas com o papel dela na produção de sentidos ou efeitos. "[...] trata-se de analisar porque aquilo é dito, daquela forma, em determinado tempo e contexto, interrogando sobre as 'condições de existência' do discurso" (SALES, 2014, p. 127). Segundo Foucault,

[...] a produção do discurso é ao mesmo tempo controlada, selecionada, organizada e redistribuída por certo número de procedimentos que têm por função conjurar seus poderes e perigos, dominar seu acontecimento aleatório, esquivar sua pesada e temível materialidade (FOUCAULT, 2009, p. 8-9).

O autor nos alerta para observarmos que o discurso não é um elemento neutro e transparente, é elemento de controle e poder, pois "as interdições que o atingem revelam logo, rapidamente, sua ligação com o desejo e com o poder" (FOUCAULT, 2009, p. 10). Trata-se do modo de pensar e falar sobre as coisas, num discurso histórico/contextual amparado por um sistema de instituições que impõem o que deve ou não ser dito e aceito.

Para Revel "O discurso designa, em geral, um conjunto de enunciados que podem pertencer a campos diferentes, mas que obedecem, apesar de tudo, a regras de funcionamento comuns" (REVEL, 2005, p. 37), que revelam uma "ordem de discurso", ou seja, o discurso reconhecido em um determinado período, que coloca em funcionamento a produção de saberes. São dispositivos discursivos que sustentam práticas, ecos da articulação entre o saber e o poder.

Fischer (2007) salienta que precisamos assumir que não estamos passando à margem dos problemas atuais, em todas as áreas, mas também das inúmeras possibilidades que temos de ir além do senso comum, "[...] de produzir em nós e a partir de nós mesmos formas de existência para bem mais do que nos propõem as lógicas dominantes [...]" (FISCHER, 2007, p. 51). A proposta da autora não é buscar as verdades, mas questionar, contextualizar essas verdades, ou duvidar das verdades do nosso tempo, compreendendo que somos subjetivados. É importante reconhecer que estamos imersos nos problemas e possibilidades, e falamos a partir deles.

Essa perspectiva de pesquisa educacional baseia-se em aspectos qualitativos, em que o sujeito investigador é concebido como parte integrante do processo de construção do conhecimento. Segundo Fischer, para Foucault: 
Nada há por trás das cortinas, nem sob o chão que pisamos. Há enunciados e relações, que o próprio discurso põe em funcionamento. Analisar o discurso seria dar conta exatamente disso: de relações históricas, de práticas muito concretas, que estão 'vivas' nos discursos (FISCHER, 2001, p. 198-199).

Assim, tensionamos como e quais processos e estratégias de gestão são postos em operação na produção de um determinado modo de gerir a universidade para a inclusão. O tensionamento parte da percepção da inclusão amparada numa visão normativa inquestionável e pouco problematizada, em que os avanços na democratização e expansão do acesso à universidade são representados através de números estatísticos divulgados como promissores.

\section{DISPOSITIVOS LEGAIS SOBRE INCLUSÃO NA EDUCAÇÃO SUPERIOR}

Iniciando esse tópico, evidenciamos o conceito de pessoas com deficiência presente na Lei 13.146/15, que, em seu artigo $2^{\circ}$, expressa: "Considera-se pessoa com deficiência aquela que tem impedimento de longo prazo de natureza física, mental, intelectual ou sensorial, o qual, em interação com uma ou mais barreiras, pode obstruir sua participação plena e efetiva na sociedade em igualdade de condições com as demais pessoas" (BRASIL, 2015c). A redação reproduz o artigo $1^{\circ}$ da Convenção de Nova York, promulgada no Brasil através do Decreto 6.949, de 25 de agosto de 2009, e recepcionada no país como Emenda Constitucional, de acordo com o artigo $5^{\circ}, \int 3^{\circ}$, da Constituição Federal (BRASIL, 1988). Assim, a deficiência deixa de estar localizada no sujeito, para ser considerada no contexto social que, devido à precária acessibilidade, produz limitações. É nesse cenário que as universidades necessitam aderir à proposta de inclusão.

A mais recente Convenção sobre os Direitos da Pessoa com Deficiência trata, de forma detalhada, sobre os direitos desse público. Com base no princípio da igualdade e na concepção de que a deficiência também é determinada pelas barreiras existentes nos ambientes, especifica o tratamento relacionado à acessibilidade às mulheres, às crianças, direito à vida, acesso à justiça, saúde, trabalho, educação, entre outras demandas específicas. O texto da convenção apresenta como meta “[...] adequar a legislação e as práticas administrativas para assegurar que a deficiência seja apenas mais uma característica da diversidade humana" (BRASIL, 2012, p. 11).

A percepção de que o fator limitador está no meio, e que são as ações coletivas e de políticas públicas que devem efetivar a equiparação de oportunidades, reflete nas políticas educacionais de acesso das pessoas com deficiência às universidades brasileiras e implica em responsabilização dos gestores. Sobre a inter-relação de objetivos e de entendimento dos documentos aprovados por organismos internacionais, o texto dessa convenção é o último e mais recente documento. A Convenção sobre os Direitos da Pessoa com Deficiência é um documento mais abrangente porque relaciona a deficiência à vulnerabilidade, quando somada às situações que podem agravar os riscos sociais desse grupo. Portanto, explicita o compromisso dos Estados de assegurar o pleno exercício de todos os direitos para esse grupo e "[...] tomar todas as medidas apropriadas para eliminar a discriminação baseada em deficiência" (BRASIL, 2012, p. 29).

No artigo 24 do referido documento, o texto apresenta a responsabilidade dos Estados para efetivar o direito à educação sem discriminação, com igualdade de oportunidades em todos os níveis de ensino. Para realização desse objetivo, é necessário providenciar adaptações de acordo com as necessidades individuais, apoio necessário aos estudantes e desenvolvimento acadêmico e social para atingir a meta de inclusão plena. No item 5 desse mesmo artigo, a Educação Superior é citada de forma específica:

Estados Partes assegurarão que as pessoas com deficiência possam ter acesso ao ensino superior em geral, treinamento profissional de acordo com sua vocação, educação para adultos 
e formação continuada, sem discriminação e em igualdade de condições. Para tanto, os Estados Partes assegurarão a provisão de adaptações razoáveis para pessoas com deficiência [...]. (BRASIL, 2012).

O discurso da educação como um "direito de todos", escrito, reescrito, ratificado no sentido de que as instituições formais de ensino devem atender a todos que chegam, passa a ser mais incisivo e se transforma em processo de aceitação no sistema das pessoas com deficiência, com movimento de busca e resgate dos jovens que estão fora do sistema. Fica explícita a cobrança ao gestor, no sentido de assumir o compromisso com a inclusão e na promoção de ações que envolvam toda a comunidade acadêmica nesse propósito.

A legislação educacional vai direcionando as ações para a inclusão, a imperatividade da norma fica explícita no artigo $8^{\circ}$ da Lei $n^{\circ} 7.853 / 89$, ao destacar que constitui crime punível com reclusão de 2 (dois) a 5 (cinco) anos e multa: I - "recusar, cobrar valores adicionais, suspender, procrastinar, cancelar ou fazer cessar inscrição de aluno em estabelecimento de ensino de qualquer curso ou grau, público ou privado, em razão de sua deficiência". A recorrência normativa da inclusão construída na perspectiva de um direito inquestionável também ganhou força através da coerção, do controle, da punição e da avaliação. A redação desse artigo foi ratificada recentemente pela Lei $\mathrm{n}^{\circ}$ 13.146, de 2015, conhecida como Estatuto da Pessoa com Deficiência.

Destacamos que as primeiras iniciativas legais para abordar a inclusão de estudantes com deficiência na Educação Superior datam de pouco mais de vinte anos e surgem sutilmente, ganhando crescente expressividade com o passar do tempo.

A Portaria n. 1.793, de dezembro de 1994, foi uma das primeiras iniciativas do Ministério de Estado da Educação e do Desporto, recomendando, em seu artigo $1^{\circ}$, a inclusão da disciplina "aspectos ético-políticos educacionais da normalização e integração da pessoa portadora de necessidades especiais", prioritariamente nos cursos de Pedagogia, Psicologia e em todas as licenciaturas.

A essa Portaria, segue-se o Aviso Circular n. 277/MEC/GM, de maio de 1996, por meio do qual o Ministério da Educação sugeriu às reitorias das IES esforço para facilitar o acesso às pessoas com deficiência. O texto propõe ações favorecedoras ao processo de ingresso no Ensino Superior, especialmente no vestibular, e orienta que as IES promovam serviços educacionais e adequações na infraestrutura, bem como providenciem capacitação de recursos humanos.

Com relação às normativas legais, destacamos também a Portaria MEC/GM n. 3.284 de 7 de novembro de 2003 que "dispõe sobre requisitos de acessibilidade de pessoas portadoras de deficiência, para instruir os processos de autorização e de reconhecimento de cursos e de credenciamento de instituições".

A estas normas, inúmeras são somadas, cuja menção não pretendemos esgotar neste texto. Citamos, apenas, mais algumas que impactaram no contexto da Educação Superior, a exemplo do Decreto $n^{\circ} 5.296 / 04$, que estabelece normas e critérios básicos para a promoção da acessibilidade das pessoas com deficiência ou com mobilidade reduzida; do Decreto-lei n. 5.626/05, que, em seu artigo $3^{\circ}$, insere a Língua Brasileira de Sinais (LIBRAS), como disciplina obrigatórias nos cursos de formação de professores, (Licenciaturas, Pedagogia e Educação Especial) e optativa aos estudantes dos demais cursos de Educação Superior e na Educação Profissional. Sendo assim, mesmo que para os estudantes estudar Libras seja optativo, a IES fica obrigada de inserir esse componente nos currículos de graduação. Este é um item presente nos instrumentos de avaliação para reconhecimento ou renovação de reconhecimento dos cursos e credenciamento ou recredenciamento da IES. Vários aspectos vinculados à inclusão e acessibilidade estão presentes nos Instrumentos de Avaliação Institucional Externa, que orientam os atos de credenciamento. Tais requisitos estão mais visíveis no Instrumento de Avaliação de Cursos de Graduação Presencial e a Distância, publicado (atualizado) em agosto de 2015 pelo Ministério da Educação (BRASIL, INEP, 2015b), que apresenta alteração nos requisitos legais e normativos. Esses requisitos são regulatórios e seu atendimento é obrigatório. O instrumento apresenta 17 dispositivos legais/normativos, sendo três deles relacionados à inclusão/acessibilidade de pessoas com deficiência ou mobilidade reduzida e com Transtorno do Espectro Autista (TEA).

Mais recente, o Ministério da Educação/Inep publicou nova versão do Instrumento de Avaliação de Cursos de Graduação Presencial e a Distância (BRASIL/INEP, 2017) para processos de 
reconhecimento e renovação de reconhecimento. No glossário do referido instrumento, assim como no anterior, consta o conceito de acessibilidade, transcrito da Lei 13.146/2015 - artigo $3^{\circ}$, inciso I, nos seguintes termos:

Possibilidade e condição de alcance para utilização, com segurança e autonomia, de espaços, mobiliários, equipamentos urbanos, edificações, transportes, informação e comunicação, inclusive seus sistemas e tecnologias, bem como de outros serviços e instalações abertos ao público, de uso público ou privados de uso coletivo, tanto na zona urbana como na rural, por pessoa com deficiência ou com mobilidade reduzida (BRASIL/INEP, 2017, p. 43).

$\mathrm{Na}$ sequência do instrumento, são explicitados os conceitos de Acessibilidade Atitudinal, Acessibilidade Comunicacional, Acessibilidade Digital; Acessibilidade Instrumental e Acessibilidade Metodológica. Está presente, também o conceito de Atendimento Educacional Especializado (AEE) como: "Serviço da educação especial que 'identifica, elabora, e organiza recursos pedagógicos e de acessibilidade, que eliminem as barreiras para a plena participação dos alunos, considerando suas necessidades específicas"'. (BRASIL/INEP, 2017, p. 44).

A Lei $\mathrm{n}^{\circ} 13.409$, de 28 dezembro de 2016, dispõe sobre a reserva de vagas para pessoas com deficiência nos cursos técnico de nível médio e superior das instituições federais de ensino. Em seu artigo $3^{\circ}$, consta que:

Em cada instituição federal de ensino superior, as vagas de que trata o art. 1o desta Lei serão preenchidas, por curso e turno, por autodeclarados pretos, pardos e indígenas e por pessoas com deficiência, nos termos da legislação, em proporção ao total de vagas no mínimo igual à proporção respectiva de pretos, pardos, indígenas e pessoas com deficiência na população da unidade da Federação onde está instalada a instituição, segundo o último censo da Fundação Instituto Brasileiro de Geografia e Estatística - IBGE. (BRASIL, 2016).

Ao destacarmos alguns dos dispositivos legais que tratam da inclusão de estudantes com deficiência na Educação Superior, salientamos o que afirmam Silva, Cymrot e D’Antino (2012, p. 669), em relação ao reconhecimento de avanços na área jurídica. Os autores reconhecem os méritos de tais dispositivos, entretanto, acreditam que "[...] por si sós, não alteram a realidade social, caracterizada por posições divergentes e práticas contraditórias no interior de instituições educacionais autodenominadas 'inclusivas"”. Para os autores:

O debate está posto pelas políticas educacionais em curso, cabendo às universidades ampliar sua produção e difusão de conhecimentos, informando à comunidade suas práticas com os graduandos com deficiência que a ela têm acessado. Se por força da legislação as barreiras arquitetônicas têm sido enfrentadas paulatinamente, há de se investigar possíveis barreiras de outra natureza vivenciadas pelo corpo docente, dificultadoras da permanência do graduando, explicitando, desse modo, o papel por ela cumprido no processo de inclusão universitária da ínfima parcela de graduandos com deficiência que tem atingido o $3^{\mathrm{a}}$ grau após ter vencido a seletividade da educação básica (SILVA; CYMROT; D’ANTINO, 2012, p. 669).

Citar esses documentos nos ajuda a compreender como a inclusão vem sendo construída como um projeto social e educacional na contemporaneidade. $\mathrm{O}$ arcabouço de normas internacionais reflete em normas internas do Brasil e reverbera em mudanças que implicam em ações das políticas governamentais e da gestão das instituições de ensino para chamar e acolher aos que estão fora do sistema escolar. Contudo, a inclusão de forma genérica merece ser tensionada para que o sujeito da inclusão, suas necessidade e singularidades ganhem o espaço necessário, desobrigando-o da normalização. É preciso compreender a inclusão como um processo multifacetado, cuja responsabilidade é das mais diferentes esferas sociais, o que produz limites de resoluções rápidas na gestão universitária. 


\section{NARRATIVAS DOS GESTORES ACERCA DA INCLUSÃO DE ESTUDANTES COM DEFICIÊNCIA NA UNIVERSIDADE}

Ao solicitar aos gestores para narrarem o que pensam da expansão do ingresso de estudantes com deficiência na universidade, e como as universidades se estruturam para atender às demandas de inclusão e acessibilidade, emergem nos discursos tensionamentos e silenciamentos. A percepção dos gestores acerca da presença do estudante com deficiência na universidade reflete o discurso da educação como direito de todos, naturalizado e inquestionável. Para o mesmo questionamento, emergem também narrativas que refletem as situações de dúvidas e angústias sobre esse processo. As falas demonstram as multiplicidades, as imprevisões, as miríades de acontecimentos existentes no contexto educacional.

Os gestores relatam situações em que, para não serem questionados e pressionados, deixam transparecer que "está tudo bem". São subjetivados para narrar a inclusão como algo necessário, uma proposta que pressupõe o engajamento de todos, e, apesar das dificuldades que a inclusão demanda, a narrativa que se destaca nesse contexto é: "precisamos dar conta" (Gestor A1). Questionado acerca de como avalia a inclusão de estudantes com deficiência na educação superior, ele relata:

Eu sou a favor, pois acho que se não tivesse esses movimentos a gente não teria chegado onde chegamos. [...] Acho importante para a gente criar uma rotina institucional, pois precisamos dar conta. (Gestor A1).

As narrativas dos gestores, ancoradas nos princípios do direito assegurado à educação, expressam a responsabilização institucional com a inclusão, como é possível observar nas narrativas que seguem:

[...] é fundamental ter eles conosco, pois sem eles não teríamos avançado. (Gestor A1);

[...] acho que se não tivéssemos essa pressão a nível federal, a instituição sozinha não iria se virar. Ia ser mais uma coisa deixada de lado, a ser esquecida. A legislação macro vem com força, impõe. [...] O MEC nos cobra dois relatórios semestrais do que é feito. (Gestor A1).

Em relação às mudanças e às adaptações, elas são bem positivas, até porque todos se beneficiam. (Gestor B2).

A instituição está recebendo esses estudantes de forma bem harmônica, e não é uma coisa para nós, meu Deus, como vamos fazer!! Aqui dentro é tudo tão tranquilo, eu acho que falando assim você pode perceber. (Gestor D1).

No campo da educação, alguns discursos funcionam como promessa de resolução dos problemas sociais, fundamentados por valores de igualdade, justiça e paz. E, ao falar sobre a sua percepção acerca da expansão do ingresso de estudantes com deficiência na universidade, os gestores relatam os discursos das normativas da inclusão como um direito humano, moral, imperativo e inquestionável.

Em decorrência da imposição de práticas inclusivas que compõem uma série de estratégias, termos específicos, as falhas e as dificuldades, às vezes, são negadas ou silenciadas e o discurso da inclusão, como direito, torna-se uma afirmação autojustificada. Contudo, constatamos, também, narrativas de tensionamentos e conflitos vivenciados nas práticas de gestão, somadas às experiências como docente (uma vez que seis dos oito entrevistados exercem os dois papéis na universidade), a exemplo do que explicitam os Gestores A2 e C1.

Como é que a gente dá conta de uma diversidade de demandas de uma universidade que está em seis lugares? Porque uma coisa é você ter que prover isso em um lugar só. Temos sete tradutores de Libras e sabemos que não atendemos. E investimentos? Porque a gente vai ser cobrado por isso. Só que não somos nós que determinamos o tamanho de recursos repassados para a universidade para investir (Gestor A2).

Na minha percepção, inclusão é o compromisso com a aprendizagem, com o bem-estar desse estudante e, eu digo, nem todos precisam estar nos mesmos lugares: se aquele espaço gera 
pressão, sofrimento, porque aquele estudante que tem uma deficiência, intelectual, acentuada, por exemplo, que não consegue se apropriar do cálculo, como estar em um curso de engenharia? Temos que nos perguntar se ele precisa estar ali, se ele pode e quer estar. Às vezes, é o desejo da família. (Gestor C1).

A crítica que emerge desse discurso aborda a padronização dos sujeitos, a ideia de que todos devem estar nos mesmos lugares e que há de se incluir na universidade em decorrência de um desejo de estar em um espaço atualmente valorizado pelos jovens e suas famílias. Aqui, cabe evidenciar que estar na universidade vai ao encontro do desejo de padronização, lugar de construção do saber, considerado privilegiado socialmente. Isso gera uma falsa ideia de que estar na universidade pode apagar ou amenizar a deficiência, rumo à intenção da desejada igualdade, da inclusão de todos. A narrativa que segue problematiza a lógica da padronização.

Dependendo do grau da deficiência, a pessoa consegue superar e conviver com a deficiência, ter uma formação e exercer a profissão depois. [...] Mas, a deficiência pode não permitir que ele execute a profissão depois. Tem os dois lados. A visão que eu tenho é que uma padronização de coisas tem que incluir todo mundo, e não é bem por aí. Os iguais são iguais e os diferentes são diferentes. Quando a gente ignora isso, fere a individualidade, fere e acaba excluindo. Acontece que a pessoa não tem potencialidade para algumas atividades, mas tem para outras. No entanto, a gente quer que ela faça tudo. Ninguém consegue desenvolver tudo. Tem potencialidades que mesmo pessoas que não têm deficiência não conseguem desenvolver. (Gestor B2).

O Gestor B2 prossegue em seu discurso, comentando a obrigatoriedade da instituição em se adequar, e que é preciso discutir as finalidades da universidade, as especificidades dos seus cursos para receber as pessoas com deficiência. Salienta que, sendo a universidade um espaço de profissionalização, é necessário pensar no que é exigido para cada área do conhecimento, pois as habilidades requeridas para cada profissão são específicas.

A especificidade de cursar uma graduação é comentada pelo Gestor B3, quando questiona a possibilidade de um estudante com deficiência intelectual dar conta de conceitos complexos exigidos nos cursos de graduação.

Nesse sentido, o Gestor B3 tensiona a inclusão somente como socialização, ao mencionar práticas por ele percebidas:

[...] coloca todo mundo, e mesmo aquele que não está aprendendo está passando de ano. É isso que está acontecendo no ensino fundamental em muitas escolas. [...] Você só está fazendo aquela pessoa conviver, mas não está contribuindo para ela se tornar independente daqui um pouco. Você inclui no sentido que ele está se desenvolvendo, mas exclui no sentido de conhecimento. [...] No ensino superior, você não vai poder fechar os olhos para os objetivos que o aluno deverá atingir ao final do semestre. Ele tem que desenvolver habilidades e competências no final do curso [...]. (Gesto B3).

Apesar da expressão "temos que dar conta" utilizada por alguns gestores, emergem os questionamentos sobre o papel da Educação Superior na contemporaneidade, as limitações individuais em decorrência das deficiências, dos limites das escolhas e ações dos gestores, e, também, da complexidade das demandas, pois cada caso é único. Tensionar a inclusão pressupõe desnaturalizar a crença de que o acesso a algumas tecnologias e a alguns saberes específicos podem suprir todas as necessidades e demandas da inclusão. Segundo Pieczkowski (2014, p. 182):

A ambivalência da inclusão se manifesta no fato da escola inclusiva sinalizar para princípios como temporalidade distinta, solidariedade, respeito à diferença, porém organizar-se, predominantemente, com base em princípios da Modernidade sólida, com tempos e espaços fixos para todos. Ao mesmo tempo em que o apelo do Estado é para instituições e professores inclusivos, as universidades são avaliadas por indicadores padronizados com foco nos resultados. $\mathrm{Na}$ conjuntura atual, a avaliação e a regulação assumem grande prestígio, e as 
instituições são comparadas e estimuladas a competir entre si na busca de melhores colocações. Qual o lugar, por exemplo, das pessoas com deficiência intelectual, que também estão matriculados em cursos superiores, nesse cenário?

Concordamos com o que afirma Ross, ao evidenciar a dimensão intensa e ingovernável da diferença. Para a autora:

Entendida como intensidade afirmativa, a diferença é uma força capaz de se furtar ao controle. Ainda que sempre de novo tentemos dominá-la, rotulá-la. E conseguiremos fazê-lo em parte. Conseguimos prender e aprender sempre somente mínimas partes da diferença. Ela tem muito mais a oferecer às nossas práticas educativas e às nossas experimentações de aprendizado. É nesse sentido, que precisamos questionar as lógicas arraigadas no contexto da universidade possibilitando a experimentação e vivência de algo com um sentido novo em educação, mais interessante e mais potente. Essa me parece ser a esperança mais lúcida de mudanças: micro, parciais (ROSS, 2009, p. 29).

A necessidade de criar alternativas para lidar com a diferença e a complexidade derivadas desse cenário de mudanças é apontada pelo Gestor $\mathrm{C} 1$, relacionando ao expressivo aumento de matrículas na Educação Superior nos últimos tempos. O entrevistado menciona uma publicação do MEC anunciando o aumento de $933 \%$ no número de matrículas de estudantes com deficiência no período de 2000 a 2010.

Alguns gestores questionam os efeitos da ampliação do acesso à Educação Superior, quando nas universidades, principalmente privadas e comunitárias ${ }^{2}$, alguns cursos têm mais oferta de vagas do que candidatos interessados e o processo de ingresso é realizado por meio da análise do histórico escolar. Como as notas são classificatórias e não eliminatórias, alguns estudantes têm ingressado na Educação Superior com grandes lacunas e com acentuadas fragilidades para se apropriar do perfil de egresso que as Diretrizes Curriculares Nacionais (DCN) estabelecem como necessárias para o exercício da profissão. O gestor C1 questiona a qualidade da aprendizagem de alguns estudantes com deficiência, embora essa problemática possa estar presente também em estudantes sem deficiência. O mesmo aponta que, ao analisar históricos escolares de estudantes com deficiência intelectual, observa que mesmo que não tenham se apropriado de noções lógico matemáticas elementares; de habilidade de escrita, leitura e interpretação de textos básicos, é comum identificar notas suficientes para avançar e concluir a Educação Básica com aproveitamento, na perspectiva documental. Manifestando inquietação relativa ao papel da universidade na profissionalização desses estudantes, o Gestor C1 expressa que

[...] o compromisso de uma instituição formadora é com o estudante, mas também com o serviço que esse estudante um dia vai prestar para a sociedade.

A fala do Gestor C1 instiga a pensar nos dados estatísticos publicados com base no Censo da Educação Superior de 2013 (BRASIL, 2015a), registrados no quadro nomeado "Matrículas de alunos portadores de necessidades especiais nos cursos de graduação presenciais e a distância, por tipo de necessidade especial segundo a unidade da federação e categoria administrativa das IES - 2015". No quadro são evidenciados dados relativos a 2013, publicados em 2015, em que existiam 1.683 estudantes com deficiência intelectual cursando graduação nas IES brasileiras naquele ano. Dos 1.683 estudantes, 476 estavam matriculados em instituições públicas e 1.207 em instituições privadas. Observa-se que a categoria comunitária não é reconhecida nesses indicadores, sendo incorporada como privada. Contudo, em novembro de 2013, a presidente da República Dilma Rousseff sancionou a Lei 12.881, que regulamenta o funcionamento das Instituições Comunitárias de Educação Superior (ICES). Através da nova lei, ocorreu o estabelecimento da definição, qualificação, prerrogativas e finalidades das Instituições Comunitárias.

As verdades contemporâneas da inclusão refletem os discursos da educação como direito de todos, mas também as contradições e os limites entre o direito à educação e a seleção dos que chegam à universidade, assim como as estratégias de avaliação e responsabilização dos gestores nas ações de inclusão.

Ao disseminar o discurso de que todos se beneficiam ao conviver com as diferenças, as políticas públicas de inclusão ganham força. Essas estratégias discursivas têm suporte em aspectos Educação em Revista|Belo Horizonte|v.36|e208881|2020 
filosóficos, relacionados aos princípios e valores na organização e formação da sociedade na perspectiva de ordem, respeito às leis e harmonia social. Porém, o contexto histórico contemporâneo nos mostra a contradição de vivenciar uma série de conquistas sociais, mas também de barbáries e restrições de direitos, incluindo o direito de ser diferente.

Observamos que manifestações que evidenciam inquietações não apareciam no início dos diálogos com os gestores. Mas, à medida que as entrevistas narrativas evoluíam, os sujeitos ganhavam confiança para expressar seus sentimentos, ultrapassando as falas generalizantes acerca da inclusão como direito inquestionável. Assim, gradativamente, os gestores revelam alguns entraves administrativos com os quais precisam conviver.

É sabido que para haver a licitação de algo, demora um tempo [...]. Por exemplo: entra um aluno agora na instituição e, se é uma estrutura que não está preparada para recebê-lo, vai demorar um tempo para as modificações serem feitas, pois não é de imediato. (Gestor B1).

A narrativa do despreparo profissional é recorrente, assim como a queixa de que ao disponibilizar cursos, os professores, técnicos e estudantes pouco aderem, falta adesão dos mesmos. Superar as barreiras atitudinais é elencado como um desafio maior do que superar as barreiras arquitetônicas.

[...] esse é o trabalho mais complicado de fazer, porque tendo dinheiro as adequações físicas você vai lá e faz. Agora, a formação de um corpo docente que tem toda uma trajetória, que não foi preparado para isso, é difícil (Gestor A2).

A pesquisa nos ajudou a compreender a incerteza vivida por gestores, entre "acolher" o estudante com deficiência e a pressão para construir as "habilidades e competências" relativas ao perfil do egresso indicado nas Diretrizes Curriculares Nacionais para cada profissão, e mesmo os resultados esperados pelo Sistema Nacional de Avaliação da Educação Superior (SINAES) criado pela Lei $n^{\circ}$. 10.861, de 14 de abril de 2004. O SINAES é composto pelos processos de Avaliação de Cursos de Graduação e de Avaliação Institucional que, junto com o Enade, forma o conjunto de indicadores que avaliam os cursos e as Instituições de Educação Superior (IES) de todo o Brasil. O Exame Nacional de Desempenho dos Estudantes (Enade), é considerado um dos pilares da avaliação do curso e da IES.

Estrela, autora portuguesa, comenta o contexto europeu, que nesse aspecto é similar ao brasileiro, salientando que as universidades estão sujeitas a opressões políticas e demandas contraditórias. Essas contradições, afirma Estrela, estão na expectativa de que as universidades incluam os estudantes "independentemente dos seus percursos escolares anteriores, e ao mesmo tempo pretender que se tornem extremamente competitivas e 'motores de arranque' de uma sociedade igualmente competitiva em nível global” (ESTRELA, 2010, p. 23).

Ao mesmo tempo em que a lógica da inclusão é pela solidariedade, a sociedade valoriza a competição e o mérito individual. Por isso, compreendemos que a inclusão se constitui em um paradoxo, resulta em ambivalência, uma vez que a diferença é compreendida a partir da afirmação de uma identidade, de relações de poder. Para Silva (2014, p. 100),

[...] antes de tolerar, respeitar e admitir a diferença, é preciso explicar como ela é ativamente produzida. Uma estratégia que simplesmente admita e reconheça o fato da diversidade torna-se incapaz de fornecer os instrumentos para questionar precisamente os mecanismos e as instituições que fixam as pessoas em determinadas identidades culturais e que as separam por meio da diferença cultural.

Tensionar a inclusão também requer pensar nas limitações das atividades exercidas pelos profissionais da Educação Especial, como é o caso da atividade do intérprete de Libras, principalmente quando se trata de conhecimentos de áreas específicas, que não fazem parte do contexto do intérprete. O Gestor B3 comenta os desafios para interpretar termos para os surdos, o que às vezes acontece em português sinalizado, sem domínio de conceitos, precarizando as apropriações. Reconhecer as fragilidades das ações em Educação Inclusiva faz o gestor revelar que também sente limitações. O 
Gestor B3 declara não se sentir capacitado, encontra dificuldades para atender pessoas com deficiência pois não vivenciou esta experiência antes. Afirma, também, ter dificuldades de ordem administrativa para atender às demandas dos estudantes incluídos. Esta mesma ordem de dificuldades é explicitada pelo Gestor A1:

[...] em outro campus nós temos um estudante cego no curso de Agronomia. Ele ficou cego há pouco tempo em função de um acidente. Então, tem toda uma adaptação para ele, e o Braille ele ainda não sabe. A dificuldade é em como adaptar esse material, pois ele tem muitas aulas de laboratório e de campo. [...] A opção foi a contratação de um bolsista para além de contribuir na adaptação dos materiais também acompanhar ele em algumas aulas de campo e algumas de laboratório. [....] Outro exemplo, de um outro campus, é de um estudante cego. E não tínhamos nem onde solicitar ajuda, pois o campus fica numa cidade pequena. [...] Recebemos também demanda de alguns professores com relação a alunos com deficiência que, às vezes, não tenho ideia de como resolver. (Gestor A1).

Compreendemos que a inclusão ocorre num movimento imbricado por vários discursos legais, que vão subjetivando os gestores, e que refletem a forma mais recente de gerir a inclusão, através da responsabilização, expressa pelas estratégias de controle nos processos de regulação e avaliação e outros dispositivos legais. O termo dispositivo, adotado por Foucault, diz respeito a técnicas, estratégias e formas de assujeitamento utilizadas pelo poder. Para Revel,

[...] trata-se tanto de discursos quanto de práticas, de instituições quanto de táticas moventes: é assim que Foucault chega a falar, segundo o caso, de 'dispositivos de poder', de 'dispositivos de saber', de 'dispositivos disciplinares', de 'dispositivos de sexualidade' etc... (REVEL, 2005, p. $39)$.

Agamben insere no contexto político contemporâneo o termo dispositivo adotado por Foucault, afirmando ser "[...] qualquer coisa que tenha de algum modo a capacidade de capturar, orientar, determinar, interceptar, modelar, controlar e assegurar os gestos, as condutas, as opiniões, e os discursos dos seres viventes" (AGAMBEN, 2010, p. 40).

\section{POLÍTICAS E ESTRATÉGIAS INSTITUCIONAIS PARA PROMOVER A INCLUSÃO DE ESTUDANTES COM DEFICIÊNCIA}

As universidades pesquisadas têm implantado setores especializados para tratar da inclusão de estudantes com deficiência, com distintas denominações: Núcleo de Acessibilidade - Universidade A; Direção de Administração - Universidade B; Setor de Divisão de Acessibilidade - Universidade C; Núcleo de Educação Inclusiva - Universidade D, conforme a estrutura e organização de cada instituição. As demandas recebidas e encaminhadas por estes setores são diversas, conforme ilustra o fragmento a seguir:

\footnotetext{
As minhas funções são atender às demandas em relação à temática que vem dos Campi. Gerencio uma ficha cadastral dos estudantes. É realizado atendimento aos professores. O trabalho também possui parceiros. Participo também do Conselho Municipal da Pessoa com Deficiência. Realizo o encaminhamento da compra de equipamentos. Contribuo na organização de capacitação, na organização de eventos institucionais, entre outras demandas, como encaminhar relatório das ações realizadas na instituição para o MEC e responder algumas ações para o Ministério Público (Gestor A1).
}

A estratégia de subjetivação e responsabilização dos gestores, através dos comandos do Estado, são expressos no relato dos gestores:

Tem uma resolução que diz que a universidade tem que ter um Núcleo de Acessibilidade, que nós chamamos de Divisão. Esse nosso setor foi criado não em função da lei, mas foi uma necessidade que nós sentimos para promover a inclusão na universidade (Gestor C1). 
Os gestores relatam que regularmente precisam responder a ações de acompanhamento da Procuradoria Federal, a exemplo da necessidade de contratar, prioritariamente, professores surdos para o ensino da Língua Brasileira de Sinais - LIBRAS, que deve estar inserida em todos os cursos de graduação.

A demanda chega na Procuradoria da universidade. Mas, ela remete para nós. Sou eu quem elabora a resposta e a Procuradoria envia, e, em alguns casos, é direto com nós mesmos. E, inclusive, os encaminhamentos que o Ministério Púbico sugeriu estão sendo providenciados (Gestor A1).

O gestor abraça um compromisso de promover a inclusão e acessibilidade, de transformar o espaço universitário, atendendo às demandas judiciais, dos estudantes, dos professores, da comunidade externa, da capacitação interna para professores e técnicos. Os gestores estão sob vigilância da sociedade externa, do Ministério público, do MEC/INEP, da comunidade acadêmica, na tênue linha de decisão acertada, julgada, valorizada ou não, de priorizar determinadas ações, muitas vezes em detrimento de outras. Com isso, percebe-se narrativas fiéis aos discursos legais, evidenciando a subjetivação dos gestores. Subjetivação, para Foucault "[...] refere-se ao modo pelo qual 'o sujeito faz a experiência de si mesmo em um jogo de verdade no qual está em relação consigo mesmo" (FISCHER, 1999, p. 42).

O esforço em encontrar possibilidades para fomentar a inclusão também está presente no relato sobre possibilidades de formação para os gestores.

Tivemos um evento nacional que reuniu os Coordenadores do Núcleo de Acessibilidade de todas as Instituições Federais, e quem o organizou foi a Universidade Federal do Rio Grande do Norte. E, lá percebemos que eles são uma referência (Gestor A1).

Mais uma estratégia está na formação através dos cursos, seminários e encontros que reflitam para o convencimento da comunidade acadêmica da necessidade de capacitação constante.

Quando chega um estudante cego, por exemplo, tem que explicar aos diferentes setores, secretária acadêmica, de curso, dizendo a partir de agora você vai receber um estudante com determinada deficiência, então você vai precisar operar no seguinte sentido... para atendê-lo da melhor forma (Gestor A2).

O trabalho em rede movimenta várias frentes na universidade, envolve vários profissionais e as demandas chegam a vários setores. São elaboradas Políticas de Educação Inclusiva, Portarias, Comissões e Fóruns de acessibilidade para ouvir os acadêmicos com deficiência, eventos para informar e conscientizar a comunidade acadêmica sobre deficiência. As demandas ocorrem devido à imposição da legislação, mas também pela necessidade da instituição, gerada pela presença de estudantes com deficiência, o que mobiliza a aprender com a diferença. Isso é salientado como positivo no ingresso recente desse público, na história das universidades.

Em 2010 e 2011, nós criamos uma Política de Acessibilidade para a instituição. Este setor faz a gestão das necessidades de acessibilidade da universidade, nas questões arquitetônica, de comunicação, de contratação de intérpretes para estudantes surdos, de ledores para cegos, por exemplo (Gestor C1).

Os setores especializados das instituições compõem o rol de ações para atender às demandas desse público. Conforme relato dos gestores, tais políticas apresentam como função a criação de instrumentos e programas para gerenciar e identificar os estudantes incluídos, a exemplo das fichas cadastrais dos estudantes e do acompanhamento de seus desempenhos acadêmicos. A identificação de estudantes com deficiência é realizada desde a inscrição no vestibular, ou outra forma de processo seletivo para o ingresso, prosseguindo no acompanhamento dos atos de matrícula ou no acesso a bolsas 
de estudo, quando se trata de universidades comunitárias ou privadas. A deficiência é um fator que prioriza a contemplação de bolsas de estudos na Universidade Comunitária pesquisada, resultado de uma política institucional.

Por sua vez, o Gestor D1 ilustra os movimentos inclusivos, ao relatar processos de identificação e encaminhamentos ao estudante.

Ele faz a inscrição e coloca lá como portador de necessidades especiais. Quando a gente imprime a lista dos inscritos e organiza os cadernos de provas, a gente verifica e seleciona os que são portadores de necessidades especiais. Quando a gente tem essa informação, ligamos para este aluno para saber qual é a deficiência, qual é a limitação dele e então organizamos o que ele precisa. (Gestor D1).

Este artigo não nos permite relatar extensivamente os movimentos de cada IES pesquisada no que se refere a inclusão e acessibilidade. Contudo, podemos destacar o imenso esforço observado, embora não na mesma proporção em cada universidade investigada, pois algumas se destacam mais do que outras. A Universidade Comunitária, por exemplo, menciona, por meio do Gestor C1, que não recebe recursos públicos para promover a acessibilidade. Mesmo assim, tem investido grandes valores econômicos em ações de acessibilidade e valoriza isso como um dos seus diferenciais. Salienta, ainda, que como as universidades comunitárias são mantidas, predominantemente, pelas mensalidades pagas pelos estudantes, são esses os recursos geridos para a acessibilidade. Ou seja, é necessário eleger prioridades e sensibilizar a comunidade acadêmica para a inclusão, o que nem sempre é fácil. Alguns estudantes reivindicam, por exemplo, ar condicionado nas salas, cadeiras estofadas, mais obras bibliográficas na biblioteca, entre outros confortos e investimentos, dizendo que isso beneficia à maioria, enquanto rampas, elevadores, banheiros adaptados, portas adequadas para a passagem de cadeirantes, programas de computadores com sistemas de voz para cegos, piso podotátil, impressoras em braille, vagas de estacionamento adaptadas e cobertas e contratação de intérpretes e de profissionais de apoio para estudantes com deficiência intelectual beneficiam poucos.

É nesse aspecto que os princípios da Educação Inclusiva precisam ser difundidos. No sentido de que a deficiência não está apenas no sujeito, mas em estruturas físicas e sociais precárias. Solidariedade é imprescindível no processo de inclusão. Se levarmos em consideração que "Os resultados do Censo Demográfico 2010 apontaram 45.606.048 milhões de pessoas que declararam ter pelo menos uma das deficiências investigadas, correspondendo a $23,9 \%$ da população brasileira" (IBGE, 2010, p. 73), números que incluem pessoas idosas (mas que enfrentam contestações), concluiremos que uma sociedade inclusiva e acessível beneficia a todos. Se não hoje, num futuro mais próximo para alguns e mais distante para outros e suas famílias.

\section{CONSIDERAÇÕES FINAIS}

Salientamos, neste artigo, que os discursos normativos tecem a inclusão enquanto projeto ideal de educação, construído com base nos princípios de solidariedade, justiça e igualdade, termos reiterados nos documentos que orientam a Educação Inclusiva. Inúmeras normativas legais tratam da inclusão de estudantes com deficiência e dos direcionamentos para as ações na Educação Superior.

No trabalho de escuta e leitura das narrativas, ficou evidente que os entrevistados vivem as pressões do controle do Estado através das normativas, pois as mesmas tratam de demandas que mobilizam os gestores, devido ao cargo ocupado, às expectativas sociais e às avaliações e controle das instituições. $\mathrm{O}$ compromisso do gestor produz mudanças na estrutura da universidade através das escolhas e posicionamentos dele. $\mathrm{O}$ impacto da presença do estudante gera tensionamentos, mas também abre perspectivas para a acessibilidade e inclusão, o que não aconteceria sem esse público.

Constatamos que, muitas vezes, o sucesso da inclusão é expresso e medido através de dados estatísticos, que mostram o aumento significativo desse público na Educação Superior nos últimos anos, no país. Constatamos, também, que são mais evidenciadas as mudanças estruturais, os 
valores investidos, e menos as condições de aprendizagem dos sujeitos envolvidos. Até porque este é um fator de difícil avaliação.

No processo de inclusão, os gestores são desafiados a aprender com a diferença, definir prioridades, e criar novas possibilidades de organização institucional, de espaços e tempos. Descobrem a pluralidade da inclusão, passando a compreendê-la como uma palavra de múltiplos significados, que provoca inquietações, mas também gera mobilidade, apropriação do novo e desconstrução de olhares padronizados. Deparar com a diferença provoca a ruptura com formas mecânicas de pensar e fazer a Educação Superior, ao constatar que mesmo que o estudante seja colocado em categorias (deficiência auditiva, deficiência física, deficiência intelectual, deficiência visual, deficiência múltipla, etc.) é único e possui demandas particulares.

O estudo nos mostra que a acessibilidade estrutural não é o maior desafio, mas sim lidar com barreiras atitudinais, a exemplo das lógicas paradoxais, como a competitividade, o mérito individual e a solidariedade, presentes na sociedade contemporânea

Foucault nos alerta que o pensamento não existe para consolar. Ele existe para nos abrir os olhos para os perigos de nosso tempo, para uma atitude ética e política de enfrentá-los mais do que ficar apontando soluções pretensamente generalizantes. Problematizar a inclusão não quer dizer ser contra, mas desnaturalizar obviedades a partir da percepção de que alguns saberes se tornam verdadeiros num certo tempo e lugar.

A rede de avaliação na qual as universidades estão submetidas atualmente gera a necessidade de incorporar um padrão consonante aos paradigmas do Estado. Os discursos midiáticos são potentes na produção de subjetividades que classificam as universidades em termos de qualidade, com base em indicadores que nem sempre avaliam as atitudes inclusivas, o que se torna visível nos períodos de divulgação dos resultados do Enade $/ \mathrm{CPC}^{3} / \mathrm{IGC}^{4}$, que representam, para o Estado, os indicadores de qualidade.

O que pretendemos evidenciar nesse texto é que, embora as instituições e os gestores sejam responsabilizados pela inclusão, o processo é muito mais amplo, é extensivo a toda sociedade e requer condições reais para se constituir com a efetividade necessária. Inclusão é muito mais do que benevolência, presença, ou indicadores de aumento de matrículas de pessoas com deficiência. Inclusão é o direito ao reconhecimento da diferença. É direito à aprendizagem, mas não somente à aprendizagem padronizada pelos dispositivos legais. Como a universidade pode se constituir em um lugar para todos? Poderá fortalecer-se por meio da Extensão Universitária para acolher o público que, em razão de suas características, apresenta limitações para apropriar-se de conceitos essenciais para o exercício profissional, a exemplo de pessoas com acentuada deficiência intelectual, que também têm ingressado nas universidades? São provocações para refletirmos os próximos passos.

\section{REFERÊNCIAS}

AGAMBEN, G. O que é o contemporâneo? e outros ensaios. Tradução de Vinícius Nicastro Honesko. 2. reimpr. Chapecó (SC): Argos, 2010.

ANDRADE, Sandra dos Santos. A entrevista narrativa ressignificada nas pesquisas educacionais pósestruturalistas. In: MEYER, Dagmar Estermann; PARAÍSO, Marlucy Alves (Orgs.). Metodologias de pesquisas pós-críticas em educação. 2. ed. Belo Horizonte: Mazza, 2014. p. 175-196.

BRASIL. Constituição da República Federativa do Brasil de 1988. Brasília: Diário Oficial da União, 05 de outubro de 1988. 
BRASIL. Lei n. 7.853, de 24 de outubro de 1989. Dispõe sobre o apoio às pessoas portadoras de deficiência, sua integração social, sobre a Coordenadoria Nacional para Integração da Pessoa Portadora de Deficiência - Corde, institui a tutela jurisdicional de interesses coletivos ou difusos dessas pessoas, disciplina a atuação do Ministério Público, define crimes, e dá outras providências. Diário Oficial [da] União, Brasília, DF, 25 out. 1989. p. 1920. Disponível em: http://www.planalto.gov.br/ccivil_03/leis/L7853.htm. Acesso em: 06 jul. 2018.

BRASIL. Ministério da Educação. Portaria n. 1.793, de dezembro de 1994. Recomenda a inclusão da disciplina ou inclusão de conteúdos sobre aspectos ético-político-educacionais da normalização e integração da pessoa portadora de necessidades especiais em cursos de graduação. Diário Oficial [da] República Federativa do Brasil, Brasília, DF, 28 dez. 1994, seção 1, p. 20767.

BRASIL. Ministério da Educação. Aviso Circular n. 277/MEC/GM, de 8 de maio de 1996. Dirigido aos Reitores das IES, solicitando a execução adequada de uma política educacional dirigida aos portadores de necessidades especiais. Brasília, DF, 1996.

BRASIL. Ministério da Educação. Portaria n. 3.284, de 7 de novembro de 2003. Dispõe sobre requisitos de acessibilidade de pessoas portadoras de deficiências, para instruir os processos de autorização e de reconhecimento de cursos, e de credenciamento de instituições. Diário Oficial [da] República Federativa do Brasil, Brasília, DF, n. 219, 11 nov. 2003, seção 1, p. 12.

BRASIL. Presidência da República. Casa Civil. Subchefia para Assuntos Jurídicos. Lei $\mathbf{n}^{\mathbf{o}} \mathbf{1 0 . 8 6 1}$, de 14 de abril de 2004. Institui o Sistema Nacional de Avaliação da Educação Superior - SINAES e dá outras Providências. Disponível em: http://www.planalto.gov.br/ccivil_03/_ato20042006/2004/lei/110.861.htm.

Acesso em: 05 jul. 2018.

BRASIL. Decreto n. ${ }^{\circ}$ 5.296, de 2 de dezembro de 2004. Regulamenta as Leis n. 10.048, de 8 de novembro de 2000, que dá prioridade de atendimento às pessoas que especifica; n. 10.098, de 19 de dezembro de 2000, que estabelece normas gerais e critérios básicos para a promoção da acessibilidade das pessoas portadoras de deficiência ou com mobilidade reduzida, e dá outras providências. Diário Oficial [da] República Federativa do Brasil, Brasília, DF, 3 dez. 2004. Disponível em: http://www.planalto.gov.br/ccivil_03/_ato2004-2006/2004/decreto/d5296.htm. Acesso em: 08 jul. 2018.

BRASIL. Decreto n. 5.626, de 22 de dezembro de 2005. Presidência da República. Casa Civil. Regulamenta a Lei no 10.436, de 24 de abril de 2002, que dispõe sobre a Língua Brasileira de Sinais LIBRAS, e o art. 18 da Lei no 10.098, de 19 de dezembro de 2000. Diário Oficial [da] República Federativa do Brasil, Brasília, DF, 23 dez. 2005. Disponível em: http://www.planalto.gov.br/ccivil_03/_ato2004-2006/2005/decreto/d5626.htm. Acesso em: 02 jul. 2018.

BRASIL. Decreto no 6.949, de 25 de agosto de 2009. Promulga a Convenção Internacional sobre os Direitos das Pessoas com Deficiência e seu Protocolo Facultativo, assinados em Nova York, em 30 de março de 2007. Brasília: Diário Oficial da União: 26 de agosto de 2009.

BRASIL. Convenção sobre os Direitos das Pessoas com Deficiência. Brasília, 2012. $4^{\mathrm{a}}$. ed. Disponível

em: http://www.pessoacomdeficiencia.gov.br/app/sites/default/files/publicacoes/convencaopessoascom deficiencia.pdf. Acesso em: 04 jul. 2018.

BRASIL. Presidência da República. Casa Civil. Subchefia para Assuntos Jurídicos. Lei no 12.881 , de 12 de novembro de 2013. Dispõe sobre a definição, qualificação, prerrogativas e finalidades das 
Instituições Comunitárias de Educação Superior - ICES, disciplina o Termo de Parceria e dá outras providências. Diário Oficial [da] República Federativa do Brasil, Brasília, DF, 13 nov. 2013, ed. extra. Disponível em: http://www.planalto.gov.br/ccivil_03/_ato2011-2014/2013/lei/112881.htm. Acesso em: 05 jul. 2018.

BRASIL. Censo da educação superior de 2013 - resumo técnico. Brasília, DF: INEP, 2015a. Disponível em: http://download.inep.gov.br/download/superior/censo/2013/resumo_tecnico_censo_educacao_supe rior_2013.pdf. Acesso em: 5 jul. 2018.

BRASIL. INEP. Diretoria de Avaliação da Educação Superior. Instrumento de avaliação de cursos de graduação presencial e a distância. Brasília, DF, 2015b.

BRASIL. Lei n. 13.146, de 6 de julho de 2015. Institui a Lei Brasileira de Inclusão da Pessoa com Deficiência (Estatuto da Pessoa com Deficiência). Diário Oficial [da] União, Brasília, DF, 7 jul. 2015c. p. 2. Disponível em: http://www.planalto.gov.br/ccivil_03/_ato20152018/2015/lei/113146.htm. Acesso em: 30 jun. 2018.

BRASIL. Presidência da República. Casa Civil. Subchefia para Assuntos Jurídicos. Lei $\mathbf{n}^{\mathbf{0}} \mathbf{1 3 .} 409$ de 28 dez. 2016. Altera a Lei no 12.711, de 29 de agosto de 2012, para dispor sobre a reserva de vagas para pessoas com deficiência nos cursos técnico de nível médio e superior das instituições federais de ensino. DOU de 29.12.2016. Disponível em: http://www.planalto.gov.br/ccivil_03/_ato20152018/2016/lei/L13409.htm. Acesso em: 11 jun. 2018.

BRASIL. INEP. Diretoria de Avaliação da Educação Superior. Instrumento de avaliação de cursos de graduação presencial e a distância. Brasília, DF, 2017.

COSTA, Marisa Vorraber. Uma agenda para jovens pesquisadores. In: COSTA, Marisa Vorraber (Org.) Caminhos investigativos II: Outros modos de pensar e fazer pesquisa em Educação. 2. ed. Rio de Janeiro, Lamparina, 2007. p. 139-153.

ESTRELA, Maria Teresa. Ética e pedagogia no ensino superior. In: LEITE, Carlinda (Org.). Sentidos da pedagogia no ensino superior. Portugal: CIIE/Livpsic, 2010. p. 11-28. (Coleção Ciências da Educação, 7)

FISCHER, Rosa Maria Bueno. Foucault e o desejável conhecimento do sujeito. Educação \& Realidade, Porto Alegre: FACE/UFRGS, v. 24, p. 39-59, jan./jun. 1999. (Dossiê: Perspectivas sobre o sujeito).

FISCHER, Rosa Maria Bueno. Foucault e a análise do discurso em educação. Cadernos de Pesquisa, n. 114, p. 197-223, nov. 2001.

FISCHER, Rosa Maria Bueno. Verdades em suspenso: Foucault e os perigos a enfrentar. In: COSTA, Marisa Vorraber. Caminhos investigativos II: outros modos de pensar e fazer pesquisa em Educação. 2. ed. Rio de Janeiro: Lamparina, 2007. p. 49-70.

FOUCAULT, Michel. A Ordem do Discurso. 19. ed. São Paulo: Loyola, 2009.

FOUCAULT, Michel. Microfísica do poder. Organização, introdução e revisão de Roberto Machado. 29. ed. reimp. Rio de Janeiro: Graal, 2011. 
FRANTZ, Walter. Universidade comunitária: uma iniciativa não-estatal em construção. Chapecó: Argos, 2004. (Coleção Seminário Temático Unochapecó)

IBGE - Instituto Brasileiro de Geografia e Estatística. Censo demográfico 2010: características gerais da população, religião e pessoas com deficiência. Rio de Janeiro, 2012. Disponível em: http://biblioteca.ibge.gov.br/visualizacao/periodicos/94/cd_2010_religiao_deficiencia.pdf. Acesso em: 07 jul. 2018.

MEYER, Dagmar Estermann. Abordagens pós-estruturalistas de pesquisa na interface educação, saúde e gênero: perspectiva metodológica. In: MEYER, Dagmar Estermann; PARAÍSO, Marlucy Alves (Orgs.). Metodologias de pesquisas pós-críticas em educação. 2. ed. Belo Horizonte: Mazza, 2014. p. 49-63.

MEYER, Dagmar Esterman; PARAÍSO, Marlucy Alves. Metodologias de pesquisas pós-críticas ou sobre como fazemos nossas investigações. In: MEYER, Dagmar Esterman; PARAÍSO, Marlucy Alves (Orgs.). Metodologias de pesquisas pós-críticas em educação. 2. ed. Belo Horizonte: Mazza, 2014. p. 17-24.

PIECZKOWSKI, Tania Mara Zancanaro; Inclusão de estudantes com deficiência na educação superior: efeitos na docência universitária. 2014. 208f. Tese (Doutorado em Educação) - Universidade Federal de Santa Maria, Santa Maria, 2014.

PIECZKOWSKI, Tania Mara Zancanaro; NUJORKS, Maria Inês. Inclusão no ensino superior: discursos e expectativas de estudantes com deficiência. In: Educação, inclusão e acessibilidade: diferentes contextos. PIECZKOWSKIM, Tania Mara Zancanaro; NAUJORKS, Maria Inês (Orgs.). Chapecó. Argos, 2014. p. 129-161.

REVEL, Judith. Michel Foucault: conceitos essenciais. São Carlos: Clara Luz, 2005. ROSS, Ana Paula. Sobre a (in) governabilidade da diferença. In: LOPES, Maura Corcini.

HATTGE, Morgana Domênica. Inclusão escolar: conjunto de práticas que governam. (Org.). Autêntica. Belo Horizonte, 2009. p.13-29.

SALES, Shirlei Rezende. Etnografia + análise do discurso: articulações metodológicas para pesquisar em Educação. In: MEYER, Dagmar Estermann; PARAÍSO, Marlucy Alves (Orgs.). Metodologias de pesquisas pós-críticas em educação. 2. ed. Belo Horizonte: Mazza, 2014. p. 113-134.

SILVA, Ani Martins; CYMROT, Raquel.; D’ANTINO, Maria Eloisa Famá. Demandas de docentes do ensino superior para a formação de alunos com deficiência. Revista Brasileira de Estudos Pedagógicos, Brasília, v. 93, n. 235, p. 667-697, set./dez. 2012.

SILVA, Tomaz Tadeu da. A produção social da identidade e da diferença. In: SILVA, Tomaz Tadeu da. (Org.). HALL, Stuart; WOODWARD, Kathryn. Identidade e diferença: a perspectiva dos estudos culturais. 15. ed. Petrópolis, RJ: Vozes, 2014. p. 73-102.

VEIGA-NETO, Alfredo. Olhares... In: COSTA, Marisa Vorraber. (Org.) Caminhos investigativos I: novos olhares na pesquisa em educação. 3. ed. Rio de Janeiro: Lamparina, 2007. p. 23-38.

\section{NOTAS}


1 As abordagens e os instrumentos metodológicos utilizados obedeceram aos procedimentos éticos estabelecidos para a pesquisa científica em Ciências Humanas.

2 a) [...] são instituições públicas não estatais, surgidas de iniciativas essencialmente comunitárias, e definidas como não confessionais, não empresariais, e sem alinhamento político-partidário ou ideológico de qualquer natureza.

b) Desenvolvem um serviço educativo e científico sem fins lucrativos, sendo todos os seus excedentes financeiros reaplicados em educação, só em território nacional. [...].

c) As atividades de ensino, pesquisa e extensão, desenvolvidas por essas instituições, têm uma vinculação privilegiada com a comunidade regional, destacando-se projetos ligados à promoção humana e social de segmentos excluídos ou de camadas da população de menor poder aquisitivo: menores, idosos, deficientes, analfabetos, moradores de periferia, pequenos agricultores, indígenas, doentes, presidiários etc. (FRANTZ, 2004, p. 18-19).

${ }^{3}$ Conceito Preliminar de Curso.

4 Índice Geral de Cursos.

Submetido: $16 / 07 / 2018$

Aprovado: 08/05/2019

Contato:

Nome completo: Joana Maria de Moraes Costa

Rua Endereço: Rua João Cherobin, 362 E, Bairro Presidente Médici, Chapecó/SC/Brasil

CEP 89.806.121 